\title{
AVALIAÇÃO QUALITATIVA DA PRODUÇÃO ENXUTA E A IDENTIFICAÇÃO DE PERDAS NA PEQUENA EMPRESA: ESTUDO DE CASO EM UMA FABRICANTE DE CENTRAIS TELEFÔNICAS
}

\section{QUALITATIVE ASSESSMENT OF LEAN PRODUCTION AND IDENTIFICATION OF LOSSES IN SMALL BUSINESS: A CASE STUDY IN A CENTRAL TELEPHONE MANUFACTURER}

\author{
Giana Carli Lorenzini ${ }^{1}$; Tarcísio Abreu Saurin²; Fernando Gonçalves Amaral ${ }^{3}$ \\ ${ }^{1}$ Universidade Federal do Rio Grande do Sul - UFRGS - Porto Alegre - Brasil \\ giana@producao.ufrgs.br \\ ${ }^{2}$ Universidade Federal do Rio Grande do Sul - UFRGS - Porto Alegre - Brasil \\ saurin@ufrgs.br \\ ${ }^{3}$ Universidade Federal do Rio Grande do Sul - UFRGS - Porto Alegre - Brasil \\ amaral@producao.ufrgs.br
}

\begin{abstract}
Resumo
O presente estudo teve por objetivo avaliar as sete principais perdas nos processos produtivos de uma pequena empresa a partir do Sistema de Gerenciamento Lean. Seguiu uma metodologia exploratória, qualitativa, realizada através de estudo de caso em que foram cruzadas a análise de informações obtidas através de visitas de observação na empresa; entrevistas com gestores; e aplicação de uma lista de verificação em implementação de práticas lean. Os resultados apontaram as perdas em relação ao contexto nacional de tecnologia de pequenas e médias empresas (PMEs), avançando sobre um campo de estudo ainda em aberto e necessário no Brasil. Destacou-se o fato de a empresa adotar algumas práticas de produção enxuta, associadas a uma composição empurrada de produção, tradicional neste tipo de indústria. Nesse contexto, as principais perdas identificadas superprodução, processamento, espera, estoque, produtos defeituosos - foram condizentes com a realidade de fraqueza na integração com a cadeia de fornecedores, no balanceamento da produção e na continuidade da produção.
\end{abstract}

Palavras-chave: avaliação qualitativa; pequenas e médias empresas; sistema de gerenciamento lean.

\section{Introdução}

Reconhecido e difundido (WOMACK; JONES; ROOS, 1992; DE TREVILLE; ANTONAKIS, 2006; FURINI; SAURIN, 2008; SCHERRER-RATHJE et al, 2009), o gerenciamento enxuto da produção associado a um aumento da competitividade ganhou espaço global junto a executivos, pesquisadores e corporações (HINES et al, 2004; VEIGA et 
al, 2008), sendo também identificado genericamente como Sistema de Gerenciamento Lean (EMILIANI; STEC, 2005). Pode-se entender o Sistema de Gerenciamento Lean como uma estratégia de negócios focada em aumentar a satisfação do consumidor final por meio de um conjunto de princípios e práticas que promovem a melhoria contínua (kaizen) através da redução de perdas produtivas em nível corporativo (SCAFFEDE, 2002; SHAH; WARD, 2003; LAUGEN; BOER, 2007; LEAN INSTITUTE BRASIL, 2011).

Orienta-se pelo propósito de criar valor aos clientes com os custos mais baixos, através da identificação de melhoria de processos por meio do envolvimento de pessoas qualificadas, motivadas e com iniciativa (LEAN INSTITUTE BRASIL, 2011). O suporte do gerenciamento lean prima pela simplicidade e clareza dos processos e ferramentas a todos os envolvidos, gerando vantagens econômicas na sua implementação (SILVA NETO, 2000). Seus princípios incluem a melhoria contínua associada ao desenvolvimento de lideranças (EMILIANI, STEC, 2005), ao passo que as práticas “envolvem a criação de fluxos contínuos e sistemas puxados, baseados na demanda real dos clientes, a análise e melhoria do fluxo de valor das plantas e da cadeia completa, desde as matérias-primas até os produtos acabados" (LEAN INSTITUTE BRASIL, 2011). Assim, além de ferramentas, tem-se também uma filosofia corporativa de aprimoramento continuado que passou a servir de referência para empresas em todo o mundo (LIKER; MEIER, 2006; BHASIN; BURCHER, 2006 apud VEIGA et al, 2008; SCHERRER-RATHJE et al, 2009).

Os benefícios da gestão lean visam abranger a empresa de forma holística. Incluem alta qualidade em produtos e serviços, ganho de market share, aumento de receitas, expansão da margem de lucro, alta produtividade, foco no consumidor, resposta rápida a mudanças de mercado e alta eficiência de ativos (EMILIANI, STEC, 2005). Tais benefícios são o objetivo de muitas organizações que competem em um ambiente rápido e complexo: novos players em mercados estabelecidos, surgimento de novas tecnologias, novos modelos de negócio sendo implantados em mercados maduros, poder de barganha com clientes e fornecedores, ameaça de substitutos e concorrência acirrada (PORTER, 1997; LAUGEN; BOER, 2007). Entretanto, para que os benefícios do Sistema de Gerenciamento Lean sejam percebidos na empresa, é necessário que se tenha claro o conceito de sete perdas da produção (SHINGO, 1996; OHNO, 1997; LIKER; MEIER, 2006; DE TREVILLE; ANTONAKIS, 2006), tema a partir do qual este estudo compõe sua análise.

Na concepção lean, perda (ou muda, em japonês) é definida por qualquer atividade que soma custos, mas não adiciona valor percebido pelo consumidor final (OHNO, 1997; WOMACK; JONES; ROOS, 1992; EMILIANI; STEC, 2005; LIKER; MEIER, 2006). Liker e 
Meier (2006) apresentam as sete principais perdas, definidas em: superprodução - itens produzidos em excesso ou antecipação às necessidades de mercado; espera - pessoas/ operadores esperando por máquinas ou processos anteriores; transporte - movimentações de materiais, peças, produtos entre processos; processamento - excesso de processos e problemas de projeto que podem causar defeitos e outras perdas; estoque - excesso de matéria-prima e/ ou produtos acabados; movimentação - deslocamentos desnecessários de operadores durante o processo produtivo; defeitos - defeitos na produção, causando retrabalho, parada de produção e necessidade de correção. Identificar perdas no processo produtivo é um primeiro passo importante para empresas que querem se aprimorar e melhorar suas chances de competir. O Sistema de Gerenciamento Lean, portanto, auxilia as empresas a enxergá-las e eliminá-las (SHAH; WARD, 2003; 2007; VEIGA et al, 2008).

Conforme afirma Silva Neto (2000), a organização ideal deixou de ser a grande empresa rígida e hierarquizada, passando a ganhar destaques nas corporações flexíveis e adaptáveis às demanda de mercado. Nesse contexto, para as PMEs, o Sistema de Gerenciamento Lean pode representar um fator fundamental de sobrevivência. Em se tratando de empresas desse porte, há uma lacuna na identificação de princípios lean e na implementação das ferramentas em PMEs de modo qualitativo, ao mesmo tempo em que também não há um entendimento claro da identificação das sete principais perdas no processo produtivo. Considerando o cenário atual de frequentes mudanças e a lacuna identificada, este trabalho propõe como objetivo principal avaliar as sete principais perdas no processo produtivo de uma pequena empresa a partir do Sistema de Gerenciamento Lean, tendo por base a identificação das sete perdas de produção, conforme definidas por Liker e Meier (2006).

\section{Sistema de gerenciamento lean em PMEs nacionais}

No Brasil, o Sistema de Gerenciamento Lean foi inserido na realidade de grandes corporações a partir da importação de processos adotados pelas multinacionais e líderes em seu setor. As modificações no paradigma econômico nacional, entretanto, fizeram com que a pesquisa e desenvolvimento deixassem de pertencer apenas às grandes corporações, tornandose fator competitivo a empresas de menor porte (SILVA NETO, 2000; LIMA; ZAWISLAK, 2003). A proposta lean corrobora que o desenvolvimento produtivo seja acessível a empresas de diferentes portes, atuantes em variados ramos de negócio (LEAN INSTITUTE BRASIL, 2011). De acordo com autores (OLAVE; AMATO NETO, 2001; ACHANGA et al, 2006), as 
PMEs passaram a incorporar tecnologia de ponta em seus processos produtivos, além de modificar sua estrutura organizacional interna de modo a se reestruturarem e competirem em cenário dominado por empresas de maior porte. Aspectos que estão diretamente relacionado ao caráter das inovações tecnológicas, com especial destaque à indústria eletrônica, robótica e informática.

Apesar dessa evolução, as PMEs costumam ser muito vulneráveis às mudanças frequentes de cenário, principalmente quando há poucas barreiras para novos entrantes, precisando assim atuar de modo reativo ao mercado (ACHANGA et al, 2006). Além disso, são raros os casos de empresas desse porte que se destacam por terem implementado a produção enxuta como filosofia corporativa. Normalmente, observa-se a aplicação de ferramentas - que não suprem a necessidade de real otimização disciplinada e controlada como um todo em processos e equipes (SCAFFEDE, 2002) - somada a uma falta de convicção das PMEs em relação à completa gestão lean (ACHANGA et al, 2006). Por outro lado, as PMEs são elemento importante na garantia da sustentabilidade industrial de um país e alvo de desenvolvimento de estratégias governamentais. No setor de tecnologia, as PMEs têm se destacado por serem menos burocratizadas e conseguirem suprir demandas deficientes de organizações maiores, entretanto, para isso precisam investir muito em qualidade e na otimização de processos.

Vislumbra-se que, além das dificuldades geradas pela legislação brasileira e os altos custos em criar e manter uma empresa, ainda há fatores como a falta de mão-de-obra qualificada no ramo; o investimento elevado em maquinário; o pouco poder de barganha com fornecedores internacionais. A fim de diminuir entraves iniciais, universidades - públicas e privadas - têm incubado PMEs, oferecendo-lhes oportunidades dentro de um ambiente que alia academia e corporação em prol de benefícios mútuos como mais investimentos governamentais, reconhecimento e diminuição de taxas e impostos. Ao mesmo tempo em que isso favorece o desenvolvimento das PMEs no País, também abre a possibilidade de estudos na área, para que se visualize a contextualização lean em uma perspectiva nacional (NARETTO et al, 2005).

\section{Procedimentos metodológicos}

Com base na apropriação de conceitos extraídos de estudos referenciais sobre Sistema de Gerenciamento Lean, a presente pesquisa seguiu procedimentos metodológicos qualitativos. Foi realizado um estudo de caso (YIN, 2009) em uma empresa de pequeno a 
médio porte, situada em um polo tecnológico da Região Metropolitana de Porto Alegre com ênfase na definição das sete principais perdas no processo produtivo e na sua aproximação com a realidade das PMEs de tecnologia no Brasil.

Conforme define Yin (2009), o estudo de caso aproxima o pesquisador de situações reais e significativas por permitir o uso de diferentes fontes de evidência como observação, entrevistas análise de documentos, ainda que tenha limitações na generalização de seus resultados. É indicado para eventos contemporâneos, sobre os quais não se tem controle direto ou clareza de conhecimentos. Como método de pesquisa reconhecido, o estudo de caso é ideal para esta pesquisa, visto que ainda não existem muitas pesquisas na área de PMEs, o que exige um maior aprofundamento a respeito do tema.

A coleta de dados ocorreu em duas etapas distintas e complementares, realizadas entre agosto e dezembro de 2011. Inicialmente, foram realizadas duas entrevistas em profundidade, com roteiro semi-estruturado e duração média de uma hora e trinta minutos: na primeira, foi entrevistado o Diretor-Presidente da companhia, para que se pudesse entender melhor o ramo de negócio da empresa, suas estratégias competitivas, sua posição no mercado e também a sua visão de produção enxuta; na segunda, foi entrevistada a Chefe de Produção, responsável por coordenar e supervisionar todos os processos produtivos, incluindo os tempos dos postos de trabalho, os testes de qualidade, o gerenciamento de estoque, programação e fechamento de ordens de produção (OPs). Essa entrevista foi realizada com o propósito de entender como a empresa organiza sua produção, seu relacionamento com a cadeia produtiva e com as equipes.

$\mathrm{Na}$ etapa posterior às entrevistas, foram feitas três observações críticas diretamente na área de produção com duração de cerca de duas horas cada. A partir disso, foi aplicado o instrumento de avaliação de produção enxuta elaborada por Ferreira e Saurin (2008). Essa ferramenta consiste em uma lista de verificação com oitenta e oito itens, organizados em doze práticas do Sistema de Gerenciamento Lean selecionadas com base em trabalhos clássicos na área. As práticas consideradas são: produção puxada e fluxo contínuo; integração da cadeia de fornecedores; nivelamento da produção; balanceamento da produção; operações padronizadas; flexibilização da mão-de-obra; controle da qualidade zero defeito (CQZD); manutenção produtiva total (MPT); troca rápida de ferramentas (TRF); gerenciamento visual; melhoria contínua; mapeamento do fluxo de valor (MFV). Seguindo os procedimentos dos autores, cada item da lista recebeu uma avaliação conforme seis critérios e seus devidos pesos: a) não se aplica $(\mathrm{NA})=$ peso inexistente; b) não existe $(\mathrm{NE})=0,0$; c) aplicação muito fraca $(\mathrm{MFR})=2,5 ; \mathrm{d})$ aplicação fraca $(\mathrm{FR})=5,0 ;$ e) aplicação forte $(\mathrm{FO})=7,5 ; \mathrm{MFO}=10,0$. Foi possível, então, calcular uma nota para cada prática, a partir da Equação 1: 


$$
\begin{gathered}
\text { Nota }=((\text { B X 2,5) }+(\text { C X 5,0) }+(\text { D X 7,5 })+(\text { E X 10,0) }) / \text { A } \\
\text { Equação } 1-\text { Notas atribuídas às práticas de produção enxuta } \\
\text { Fonte: Adaptado de Ferreira e Saurin (2008) }
\end{gathered}
$$

Na qual: (A) é igual ao número total de itens aplicáveis; (B) é igual ao número de itens com aplicação muito fraca; (C) é igual ao número de itens com aplicação fraca; (D) é igual ao número de itens com aplicação forte; e (E) é igual ao número de itens com aplicação muito forte. Optou-se por aplicar tal ferramenta em virtude do conhecimento que se tinha sobre o tema no início, somado ao tempo hábil de pesquisa. O preenchimento da lista ocorreu após três visitas de observação aos postos de trabalho do setor produtivo, com cerca de duas horas cada.

As entrevistas e a lista de preenchimento foram analisadas conjuntamente para que se pudesse contrapor a filosofia da empresa (conforme descrita pelos entrevistados) à sua realidade produtiva (observada nas visitas feitas e no preenchimento do instrumento de avaliação), considerando as ferramentas de melhoria já implantadas que se identificam com a proposta lean e as perdas evidentes no processo produtivo que ainda precisam ser minimizadas para um gerenciamento enxuto. Para consolidar os resultados prévios, estes foram apresentados e revisados juntamente com a Chefe de Produção, à qual se solicitou um parecer sobre as interpretações feitas. Além disso, dúvidas pendentes foram solucionadas. As informações foram, então, consolidadas e entregues à diretoria na forma de um relatório final.

\section{Resultados e discussão}

Os resultados obtidos a partir dos procedimentos metodológicos supracitados são discutidos a partir do entendimento da empresa, seu negócio e suas práticas produtivas, conforme exposto nas seções abaixo.

\subsection{Caracterização da empresa}

A empresa estudada é de pequeno a médio porte (SEBRAE, 2009), com matriz no polo tecnológico de uma das maiores universidades particulares da Região Metropolitana de Porto Alegre - RS. Trabalham na empresa cerca de cem funcionários distribuídos na matriz; em um escritório comercial em São Paulo - SP; em representações comerciais em diversas capitais do País. Há mais de uma década, atua no mercado de produtos de acesso em telecomunicações, orientada a produzir centrais telefônicas com tecnologia digital e IP, acompanhando o mercado de telecomunicações. Ao todo, fabrica oito famílias de produtos 
que possuem entre dois e oito produtos cada. No início, seu escopo de atuação era apenas vender centrais telefônicas com a produção totalmente terceirizada. Com o crescimento do negócio, porém, sentiu necessidade de montar seus próprios processos produtivos, tendo para isso redesenhado todos os produtos.

Atualmente, o projeto das placas é feito internamente, produzido na China e montado novamente na empresa. Cada placa tem seu próprio programa, o que influi na configuração do software para produção. Para protótipos novos, a demora para inserção no sistema pode ser de até um dia e meio, já para produtos cadastrados e programados, é feita uma busca na biblioteca de produtos, o que reduz os setups para duas horas (em caso de produtos de famílias distintas) ou quinze minutos (para produtos de mesma família). Além da sua produção, seu negócio também abrange serviços de assistência, suporte e softwares terceirizados para oferecer serviços às áreas de tecnologia da informação de seus clientes.

Sua concentração de clientes está no mercado brasileiro, embora esse ramo de negócio situe-se em âmbito global, ao qual a empresa busca se adequar atendendo a oportunidades na América Latina, África, Austrália e Irã - este último ainda em fase de projeto. A empresa enxerga seu mercado de atuação como rápido e dinâmico, exigindo aperfeiçoamento constante - no que a produção enxuta pode contribuir, ainda que até o momento esteja implantada apenas através de algumas práticas e não como ferramenta corporativa (LIKER, 2006). Por tais motivos, o nível de qualidade também precisa ser internacional, de modo a atender às necessidades dos clientes. Assim, a empresa possui um sistema de gestão de qualidade, certificado pela NBR ISO 9001 2008, certificação Anatel e FCC, somados à avaliação CMMI que destaca o padrão internacional no gerenciamento de projetos de desenvolvimento de software e hardware.

Seus concorrentes indiretos são grandes players no mercado de produtos de acesso em telecomunicações, que servem de referência para sua atuação. A fim de acompanhar a movimentação da concorrência, são feitas visitas frequentes a feiras internacionais de tecnologia. São concorrentes diretos as empresas de médio porte do ramo, as quais buscam ampliar sua fatia de mercado agregando serviços aos produtos ofertados. Destaca-se o fato de que o setor como um todo vem enfrentando dificuldades com a entrada da produção chinesa, tornando-se mais barato adquirir peças na China e montar no Brasil. Outro ponto que cria barreiras no segmento de tecnologia em âmbito global é a escassez de matéria-prima. Esse aspecto foi bastante frisado na entrevista com o Diretor-Presidente da companhia, o que ajuda a entender a relação da empresa com toda a sua cadeia de fornecimento, analisada a partir da lista de avaliação lean (FERREIRA; SAURIN, 2008). 


\subsection{Avaliação das práticas enxutas}

A avaliação das práticas enxutas através da aplicação do instrumento de verificação (apêndice A) permite comparar problemas relatados nas entrevistas com problemas identificados nas observações da produção. A Figura 1 mostra a nota obtida em cada prática. A Tabela 1 compara as notas obtidas nas práticas enxutas com as principais perdas identificadas na empresa.

Figura 1 - Notas atribuídas às práticas enxutas avaliadas

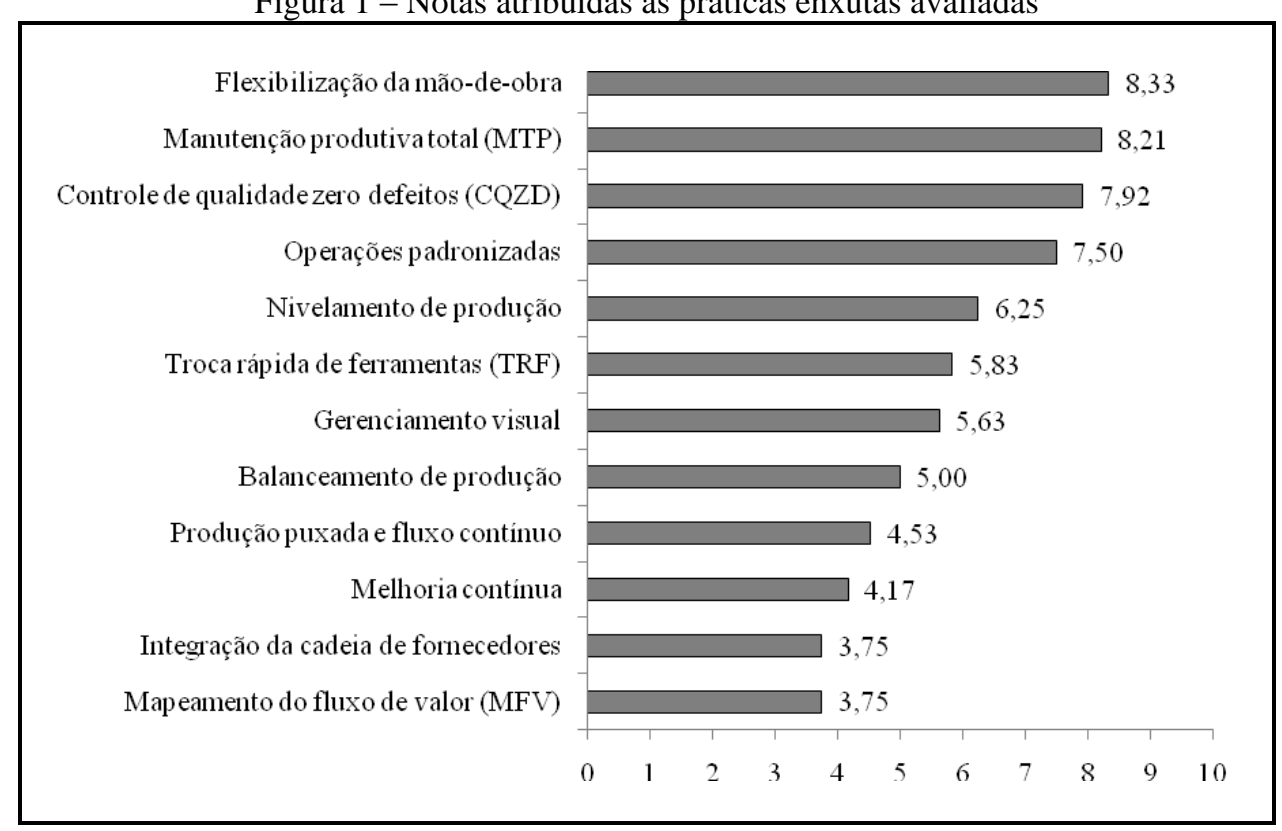

Fonte: Adaptado de Ferreira e Saurin (2008)

A fim de fornecer uma visão mais ampla sobre as notas obtidas e o contexto da empresa, além do comparativo, foi feita uma análise agrupada das práticas com base na organização da empresa (item 4.3); nos seus procedimentos de qualidade e gerenciamento visual (item 4.4); na padronização do trabalho e formação de lideranças (item 4.5); e na relação entre o sistema produtivo e as perdas identificadas (item 4.6). 
Tabela 1 - Comparativo entre as sete principais perdas e as notas obtidas na avaliação das práticas enxutas

\begin{tabular}{|c|c|c|c|c|c|c|c|c|}
\hline \multirow[b]{2}{*}{ Práticas enxutas } & \multirow[b]{2}{*}{ Notas } & \multicolumn{7}{|c|}{ Perdas } \\
\hline & & Superprodução & Transporte & Movimentação & Processamento & Espera & Estoque & $\begin{array}{c}\text { Produtos } \\
\text { defeituosos }\end{array}$ \\
\hline Mapeamento do fluxo de valor (MFV) & 3,75 & & & & $\mathrm{X}$ & & & \\
\hline Integração da cadeia de fornecedores & 3,75 & & & & $\mathrm{X}$ & $\mathrm{x}$ & $\mathrm{X}$ & $\mathrm{x}$ \\
\hline Melhoria contínua & 4,17 & $\mathrm{x}$ & $\mathrm{X}$ & $\mathrm{x}$ & $\mathrm{X}$ & $\mathrm{x}$ & $\mathrm{x}$ & $\mathrm{x}$ \\
\hline Produção puxada e fluxo contínuo & 4,53 & $\mathrm{x}$ & & $\mathrm{X}$ & $\mathrm{X}$ & $\mathrm{x}$ & $\mathrm{x}$ & $\mathrm{x}$ \\
\hline Balanceamento de produção & 5,00 & $\mathrm{x}$ & & & $\mathrm{X}$ & $\mathrm{x}$ & $\mathrm{x}$ & \\
\hline Troca rápida de ferramentas (TRF) & 5,83 & $\mathrm{x}$ & & & $\mathrm{x}$ & $\mathrm{x}$ & $\mathrm{x}$ & \\
\hline Nivelamento de produção & 6,25 & $\mathrm{x}$ & & & & & $\mathrm{x}$ & \\
\hline Gerenciamento visual & 6,56 & & & & $\mathrm{X}$ & & & \\
\hline Operações padronizadas & 7,50 & & & & $\mathrm{X}$ & & & \\
\hline Controle de qualidade zero defeitos (CQZD) & 7,92 & & $\mathrm{X}$ & $\mathrm{x}$ & $\mathrm{X}$ & $\mathrm{x}$ & & $\mathrm{x}$ \\
\hline Manutenção produtiva total (MTP) & 8,21 & & & & $\mathrm{X}$ & $\mathrm{x}$ & & $\mathrm{x}$ \\
\hline Flexibilização da mão-de-obra & 8,33 & & & $\mathrm{x}$ & & $\mathrm{x}$ & & \\
\hline Total perdas & & 5 & 2 & 4 & 10 & 8 & 6 & 5 \\
\hline
\end{tabular}

Perdas:

Superprodução - itens produzidos em excesso ou antecipação às necessidades de mercado

Espera - pessoas/ operadores esperando por máquinas ou processos anteriores

Transporte - movimentações de materiais, peças, produtos entre processos

Processamento - excesso de processos e problemas de projeto que podem causar defeitos e outras perdas

Estoque - excesso de matéria-prima e/ ou produtos acabados

Movimentação - deslocamentos desnecessários de operadores durante o processo produtivo

Defeitos - defeitos na produção, causando retrabalho, parada de produção e necessidade de correção

Fonte: Adaptado de Ferreira e Saurin (2008) 


\subsection{Organização da produção na empresa}

Na empresa analisada, a previsão de demanda é toda feita com base na previsão de vendas apontada pela área comercial para os produtos mais solicitados e assembly-to-order para os produtos menos pedidos. A previsão é feita mensalmente, considerando também os dois meses seguintes $(30+60+90$ dias). Com base no mês vigente, a produção prioriza a demanda semanal e a demanda diária. A ordem de produção (OP) é lançada no sistema, porém em mais de uma operação e por subitem, de forma não necessariamente sequenciada, já as ordens de faturamento são fechadas às $17 \mathrm{~h}$ do dia anterior e iniciam no dia seguinte. O lançamento de OPs em subitens ocorre devido ao fato de muitos componentes serem aplicáveis a mais de um produto/ família. Caso o componente esteja em estoque, o sistema o abate automaticamente, para evitar excessos. Normalmente há uma OP para montagem de máquina, uma para PTH (montagem convencional) e uma para mecânica (montagem manual).

A fórmula de dimensionamento é automatizada, de modo que a cada OP é avaliado se existe matéria-prima em estoque e a existência de produtos acabados ou não, balanceando 'planejado' versus 'concluído'. Para que haja um melhor aproveitamento, há softwares específicos que são utilizados para programar a produção. Esses programas propõem uma sequência a ser produzida com base na otimização de tempos de setup das máquinas. Essa sequência é revisada e aprovada e/ ou alterada pelo operador. Porém, por ser a demanda baseada em expectativa da área comercial, podem ocorrer demandas urgentes que influenciam e alteram a ordem de produção, como no caso do ganho de licitações. Além disso, podem ocorrer problemas como atraso na importação de componentes - um risco com o qual a empresa precisa lidar constantemente e que foi observado em uma das visitas à empresa. Nessas situações, toda a previsão de demanda semanal e mensal é revista, com rearranjos de OPs, fracionamento da produção de lotes e negociação entre Departamento de Produção e Área Comercial, a fim de remanejar prioridades.

O processo produtivo organiza-se em um layout em formato ' $U$ ', sendo que a mesma porta de entrada de materiais é também a porta de saída de produtos acabados. O processo inicia-se na linha de produção de placas com quatro máquinas principais: uma máquina printer, que funciona como uma serigrafia, na qual os componentes são gravados na placa através de um estêncil. Depois, há duas máquinas pick and place que executam a mesma função, sendo uma delas mais nova e com maior capacidade produtiva. Após, há uma máquina de refusão que funciona como um forno e uma máquina de solda em onda, nas quais os componentes são, então, soldados à placa. Além da área de máquinas, há postos de colocação manual de componentes (montagem convencional ou PTH) e uma grande área de testagem semi-manual de produtos semi-acabados e acabados. 
Identifica-se uma tentativa de construção de unidade celular devido à sua organização em função de proximidade de espaço entre postos de trabalho e fluxo de informação, atualizadas e disponíveis a todos via sistema. A produção caracteriza-se por ser empurrada e não puxada - a qual seria mais indicada em um Sistema de Gerenciamento Lean - sendo basicamente orientada a partir dos tempos de máquina. Isso contribui para um desequilíbrio no balanceamento da produção (nota 5,0) e acaba por transformar a área de testagem em gargalo, comprometendo a continuidade do fluxo (nota 4,53).

Além disso, faltam definições mais criteriosas em relação a medições de lead time, takt time e tempos de ciclo. Atualmente, os cálculos de tempo de ciclo de máquinas e mão-de-obra por produto são revisados mensalmente, através de tabelas, conforme exemplificado nas Tabelas 1 e 2 . O lead time é calculado e custeado dentro da estrutura do produto em função da demanda passada pelo comercial. Tais tempos (lead time e tempos de ciclo) são aplicados aos softwares, principalmente para controles de setups e organização das OPs. Já o takt time não faz parte do cotidiano da produção, estando apenas disponível em planilhas no sistema, sem visualização e controle diário dos operadores.

Como consequência dos ajustes imperfeitos entre demanda e tempos, postos de trabalho posteriores à linha das máquinas são sobrecarregados em virtude da otimização de setups, podendo gerar produção superior à demandada e comprometendo a lógica lean de produção unitária just-intime. A fraqueza das notas relacionadas à organização da produção mostra que falta um envolvimento adequado entre processos e pessoas, ao mesmo em que exigem um equilíbrio de tempos ainda não atingido pela organização. No nivelamento da produção obteve-se uma nota mais alta $(6,25)$, em virtude de já haver um planejamento de tempos, embora estes necessitem atualizações mais frequentes, revisão continuada e menos variabilidade.

\subsection{Procedimentos de controle de qualidade e gerenciamento visual}

A empresa realiza inspeção na fonte ao buscar um item no almoxarifado, pois é realizado um setup de conferência, antes de inicialização de processos na máquina. Isso é feito tanto através do software quanto através da vistoria do operador. Contudo, além dos recursos do próprio software, não há poka-yokes (dispositivos contra falhas) que fortaleçam essa inspeção, além disso, muitos processos exigem que a inspeção seja feita após a montagem do produto/ componente. Conforme comentado pela Chefe de Produção, o ideal seria que também houvesse uma automatização, com códigos de barras, impedindo erros humanos na alimentação das máquinas que, quando ocorrem, podem acarretar em erro na produção de placas de um lote inteiro. 
No caso de algum problema durante a montagem da placa, as máquinas têm autonomação, ou jidoka (LIKER; MEIER, 2006), para interromper o processo, da mesma forma que os operadores podem parar a linha em caso de não-conformidade. Isso é constantemente acompanhado através de monitores e andons (dispositivos visuais de advertência), conforme Figura 2, que sinalizam problemas ou paradas. Qualquer problema é imediatamente resolvido, sem continuidade até que o processo esteja $100 \%$ reestabelecido. Há também um técnico dentro da empresa, a fim de agilizar a resolução de problemas e não-conformidades.
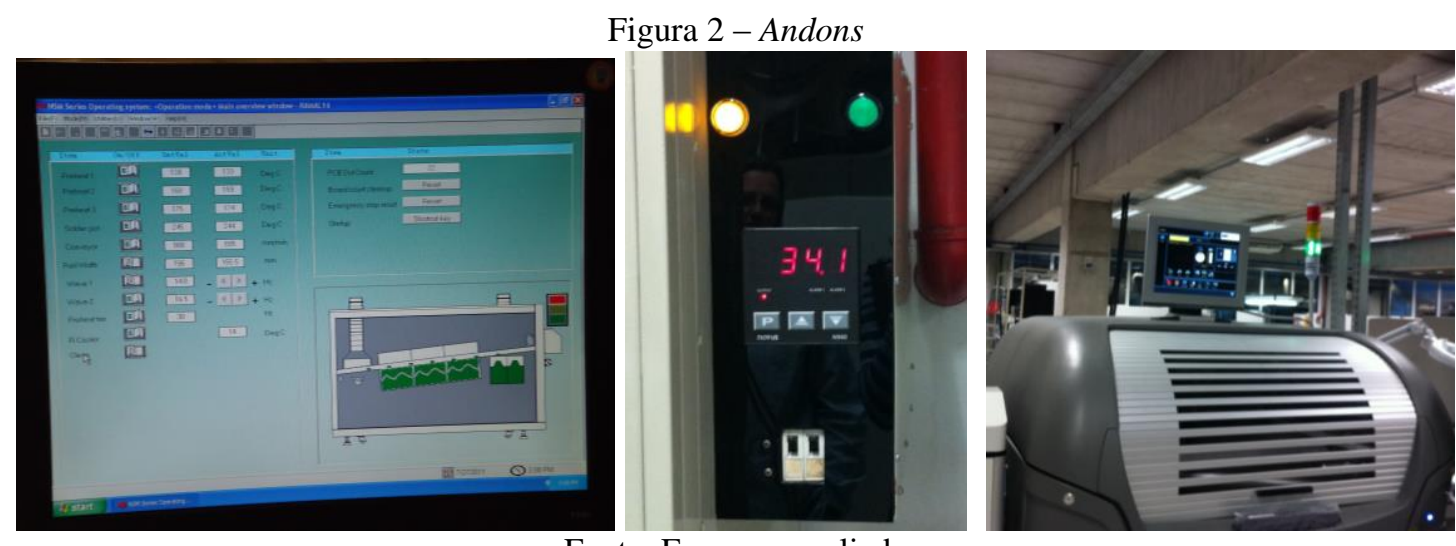

Fonte: Empresa avaliada

As máquinas ficam bem próximas entre si, o que facilita o processo. Além disso, os supermercados e ferramentas também estão próximos, o que evita grandes perdas com transporte (materiais) e movimentação (pessoas). Os fluxos entre supermercados e o armazenamento com um responsável do almoxarifado encarregado de repor as peças. Isso não é feito através de kanbans, mas sim através de avaliação visual e também das OPs disponíveis no sistema, que sugerem a quantidade necessária de peças por dia. Para identificar os itens, há adesivos com os nomes/ código da peça, porém não existe um indicador visual que sinalize com cores ou marcações a necessidade de reposição.

Não há um programa de 5S oficial, entretanto, as auditorias internas periódicas acabam exercendo papel similar. Destaque para um quadro branco (Figura 3) no qual são destacadas as demandas do dia, contudo falta um painel eletrônico ou mais informações visuais que indiquem demandas, tempos e metas. Esses pontos deficientes acabaram por reduzir a nota relativa à prática de gerenciamento visual $(6,25)$, embora a empresa preze bastante pela organização no ambiente de trabalho. 


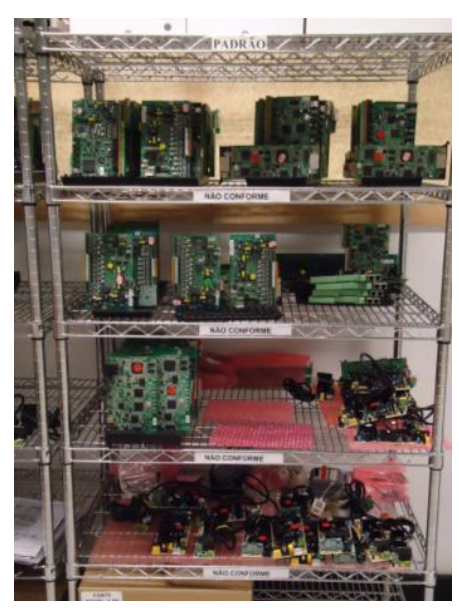

Figura 3 - Gerenciamento visual
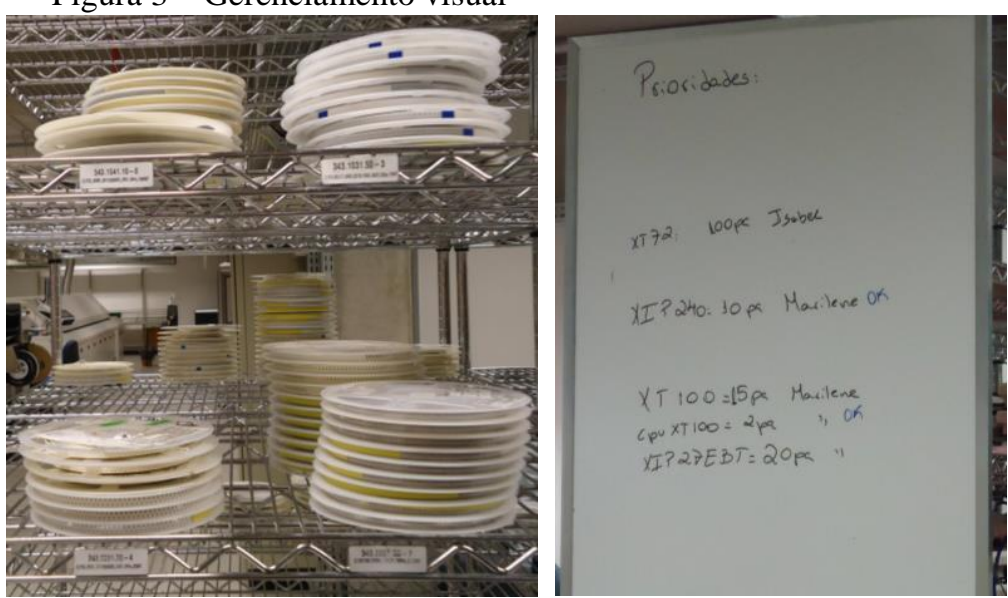

Fonte: Empresa avaliada

Assim, que a primeira placa é produzida, ela é inspecionada em $100 \%$, ou seja, todos os componentes são inspecionados minuciosamente por um operador no final da linha das máquinas, conforme modelo disponível no sistema. Essa peça serve como um gabarito e poka-yoke de controle para as demais, nas quais é feita inspeção informativa em que é avaliado se os componentes estão nos lugares certos. Na sequência, as placas passam por uma etapa manual, na qual são inseridos componentes PTH e é feita a gravação de memória. Após, são colocadas na estante para montagem da central.

Essas peças então vão para a área de testes. Elas são testadas no gabinete, uma a uma, antes de a central ser montada. Esse procedimento é adotado porque estavam ocorrendo muitos defeitos com gabinetes, enviados pelos fornecedores chineses e que não compatibilizavam com as fontes montadas na empresa. Isso, todavia, gera um processo longo de retrabalho, que poderia ser evitado se os gabinetes viessem dos fornecedores com certificação de qualidade. Além disso, na área de testes também são feitos testes com softwares. As placas com problemas são enviadas para um supermercado de peças não-conformes. Mensalmente as peças não-conformes são registradas para controle. Para executar os testes, os operadores são treinados e possuem um roteiro-padrão de procedimentos, normalmente disponível na tela do computador ou em folhas próximas ao posto de trabalho. Ao ser identificada uma não-conformidade ao final da linha, o processo também é interrompido e corrigido, para que as demais peças não saiam com o mesmo defeito. Peças conformes são enviadas ao setor de embalagem, seguindo depois para a expedição ou o estoque. A Figura 4 indica o fluxo de peças conformes e não-conformes. 


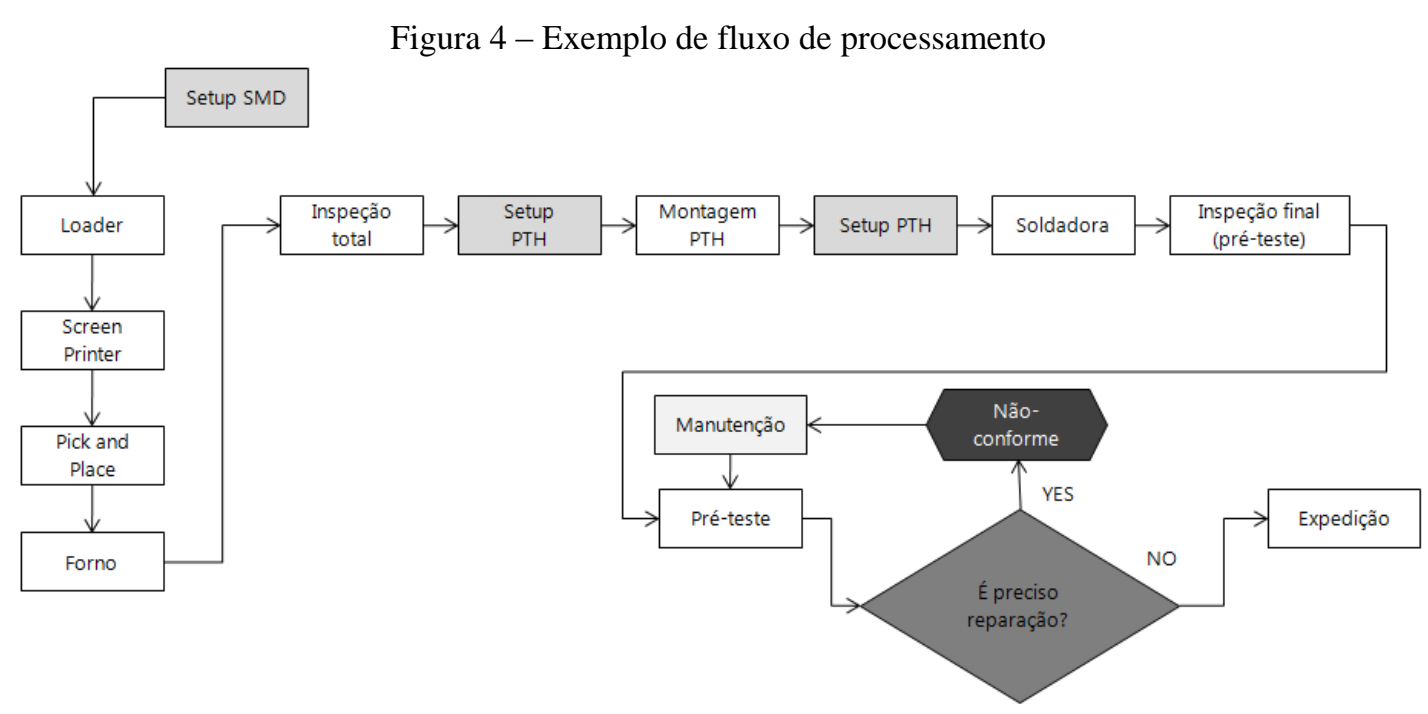

Fonte: Empresa avaliada

A empresa zela por suas certificações de qualidade, ainda que existam pontos a melhorar, de modo que todos os produtos possuem instruções de testes e indicadores de qualidade o que condiz com a nota de 7,92 nesta prática. Em relação às máquinas, a empresa opta, sempre que possível, por manutenção preventiva, na qual a cada 3.000 horas a máquina deve ser revisada. A manutenção corretiva só é feita em casos extremos, quando a máquina realmente tem problemas que a obrigam a parar para conserto. Já a efetividade operacional de equipamento não tem medições, o que compromete uma das melhores notas obtidas na avaliação, relativa à manutenção produtiva total $(8,21)$.

\subsection{Padronização do trabalho e formação de lideranças}

A empresa tem operadores multifuncionais, capacitados para realizar mais do que a sua tarefa. Os funcionários novos recebem treinamento e as atividades são ensinadas por um colega com maior experiência. Eventualmente, há workshops para atualização de grupos de funcionários. Há um mural eletrônico, disponível por acesso via computadores da empresa, para que cada um saiba e visualize os roteiros-padrão do seu posto. Normalmente, os profissionais são divididos por funções no processo de montagem na linha de máquinas e na área de testes.

Durante o período de trabalho da máquina, o operador do posto precisa ficar próximo acompanhando, caso precise adicionar insumos, para que a máquina não precise esperar a reposição. Ainda que tal prática não siga um procedimento enxuto - visto que há períodos de ociosidade no qual o operador poderia estar produzindo - tal procedimento é preferível ao invés de haver um operador distante que poderia não perceber, ou demorar a perceber a necessidade de reposição de material, o que atrasaria os demais postos de trabalhos. Na área de testes, a multifuncionalidade costuma ser mais recorrente para que as peças produzidas na montagem não precisem ficar muito tempo paradas. Essa multifuncionalidade, com rotinas padrão, já tem um bom 
nível de implantação na empresa, o que se percebe pelas notas de 8,33 em flexibilização de mãode-obra e de 7,50 em operações padronizadas.

Em relação à melhoria contínua, porém, a nota cai bastante, resultando em apenas 4,17. Percebe-se que existe uma tentativa de incentivo à participação dos operadores no aprimoramento das atividades, visto que as melhorias podem ser sugeridas pelos funcionários, sendo documentadas, e caso aprovadas pela Coordenação da Produção e Diretoria, implementadas. Contudo, a formação de lideranças fortes capazes de promover a inovação no negócio ainda é fraca e bastante restrita, com pouca ênfase no gerenciamento lean, bem como na difusão de princípios e práticas. Logo, este reflete-se como um dos pontos cruciais identificados para que a empresa possa continuar com uma curva de crescimento ascendente.

\subsection{Relação entre o sistema produtivo e as perdas identificadas}

O cruzamento entre a identificação das principais perdas e a avaliação da implementação de práticas enxutas foi feito através da comparação entre as notas obtidas e a definição de cada perda, com base no que foi observado e registrado nas entrevistas, com aprovação junto à empresa estudada (conforme já apresentado na Tabela 1). Entre as principais perdas que se destacaram, constam: superprodução, processamento, espera, estoque, produtos defeituosos. Já em relação a transporte e movimentação houve uma percepção reduzida de perdas, em virtude da tentativa de organização celular e da própria estrutura da empresa que é pequena e não conta com muitas linhas e/ ou unidades produtivas.

A perda por superprodução deve-se a duas razões principais identificadas: dificuldade de relacionamento na cadeia de suprimentos com fornecedores e setups demorados. O relacionamento com os fornecedores chineses é empurrado, o que gera pedidos em grandes quantidades e com pouca frequiência. Isso faz com que a empresa trabalhe sempre com alto volume de estoques, pois 90\% da matéria-prima é importada, vinda diretamente da China - o que está relacionado às dificuldades de insumos no setor de tecnologia, apontado nas entrevistas. Para conseguir melhores preços na compra e não correr o risco de ficar sem matéria-prima, a empresa prefere ter grandes estoques e assumir esse custo em sua produção, ao invés de perder vendas. O restante da matériaprima (10\%) provém de fornecedores nacionais, o que possibilita entregas em pequenos lotes, em modo puxado.

Por questões de proximidade logística e melhor comunicação, a cadeia de suprimentos entre empresa e fornecedores nacionais está mais próxima do Sistema de Gerenciamento Lean, todavia corresponde a um percentual pouco significativo no total de aquisições de matéria-prima. Sobretudo, a empresa opta por prezar pela satisfação do cliente em longo prazo, ainda que isso influencie em perdas no cotidiano da produção. Tal estratégia de produção, confirmada pelo 
Diretor-Presidente e pela Chefe de Produção, é característica das PMEs, que convivem com um cenário acirrado de surgimento de entrantes e também de competição em grandes empresas com maior poder de barganha. É uma estratégia que favorece a perda por estoque, mas que tem se mostrado competitiva até o momento, embora possa dificultar a sustentabilidade da empresa com a entrada de novos players, além de comprometer suas práticas enxutas, como mostrou a nota de 3,75 na integração com a cadeia de fornecedores. Visando otimizar o estoque, a empresa estipula metas anuais de matéria-prima, anual e de produto acabado, o que mostra uma tentativa de reversão desta perda.

A perda por processamento é visualizada em praticamente todas as práticas avaliadas, com exceção da flexibilização da mão-de-obra. Acontece não devido a problema na estrutura de montagem dos produtos, mas devido a problemas nos tempos entre postos e no excesso de processos de qualidade, decorrentes dos defeitos de matérias-primas e peças de fornecedores. A fraqueza no mapeamento de fluxo de valor é verificada pela nota baixa $(3,75)$ obtida, o que se revela também nas perdas existentes entre integração de tempos de processos. Tal qual apontado, isso gera sobrecarga da área de testagem, o que, por sua vez, acarreta na perda por espera, relacionada à maioria das práticas verificadas. As perdas por espera também aparecem durante as atividades das máquinas, às quais demandam de um a três operadores sempre próximos controlando o trabalho. Além disso, o posto de inspeção de qualidade informativa pode acabar gerando perda por espera, caso não haja nada para inspecionar no momento. Na área de testes, pode haver perda por espera em virtude de a produção ser empurrada e todos os tempos estarem vinculados aos tempos das máquinas.

Em relação aos defeitos na produção (perda por defeito), o índice mais recente mensal (abril de 2011) indica 1,38\% de defeito, em que de 2.896 placas liberadas para expedição, 40 apresentaram não-conformidades. Esse dado, porém, não considera o retrabalho vindo por parte do fornecedor, que implica em teste de $100 \%$ do material. A meta do ano deve fechar em no máximo 2,0\%, considerando a média entre todos os meses do ano. Quando há alterações também as peças voltam do estoque de peças prontas para ajustes de software, o que implica em retrabalho de testagem e de expedição. A empresa já teve de lidar com muitas reclamações de clientes por defeitos causados devido à falta de certificação de qualidade dos produtos chineses. Para evitar ter que fazer lotes inteiros novamente, optou por fazer inspeção $100 \%$ nos gabinetes vindos da China, aos quais são depois acopladas as placas produzidas na linha de máquinas (printer-pick\&placerefusão-sonda).

Em se tratando das perdas por transporte e por movimentação, percebe-se que são as com menor impacto negativo nas práticas enxutas analisadas, devido a algumas medidas já adotadas pela empresa para sua redução efetiva. Um dos pontos positivos identificados foi a mudança no 
transporte de materiais do estoque para a produção e entre postos de trabalho. Hoje, o armazenamento no estoque é organizado no modo first in, first out. Antes, quando surgia necessidade de buscar materiais no almoxarifado, o responsável deveria ir lá buscar os materiais. Existem pequenos supermercados ao longo do processo produtivo e o setor de almoxarifado é responsável por colocar as peças nos supermercados, que contém as devidas identificações, conforme previsão de produção diária. Carrinhos próximos a cada estação de trabalho também agilizam os acessos a materiais e transferências de peças entre postos. Conforme mencionado no item 4.4, cartões kanban não são utilizados, de modo que a Chefe de Produção relatou sentir a necessidade de códigos de barra ou algum outro mecanismo informatizado que facilitasse e agilizasse a inserção de informações a respeito de peças retiradas e peças repostas.

\section{Conclusão}

A presente pesquisa buscou avaliar a implementação de práticas enxutas em relação às sete principais perdas no processo produtivo de uma pequena empresa a partir do Sistema de Gerenciamento Lean, através de um estudo de caso de vertente exploratória e qualitativa. No geral, os resultados obtidos através da observação, das entrevistas e da aplicação da lista de verificação mostraram que a empresa tem algumas práticas de produção enxuta, contrapostas a uma composição empurrada, tradicional na indústria. Nesse contexto, as principais perdas identificadas superprodução, processamento, espera, estoque, produtos defeituosos - condizem com a realidade de fraqueza na integração com a cadeia de fornecedores, no balanceamento da produção e na continuidade da produção. A fraqueza nessas três práticas, por sua vez, acarreta em fraqueza também no mapeamento do fluxo de valor e na melhoria contínua. Práticas como troca rápidas de ferramentas, gerenciamento visual e nivelamento de produção ainda são dúbias e não se mostraram fortes o suficiente para impulsionarem a empresa.

Por outro lado, há práticas com as quais a empresa tem se aprimorado e diminuído suas perdas, como é o caso da padronização de operações, o controle de qualidade zero defeitos, a manutenção produtiva total e a flexibilização da mão-de-obra. Conforme visto no estudo de referenciais acerca de PMEs, essas práticas são fator de competitividade para empresas que concorrem em meio a gigantes do mercado. Servem como diferencial justamente por haver a possibilidade de companhias desse porte conseguirem otimizar sua força de trabalho, capacitando-a para a multifuncionalidade atrelada a um controle otimizado de processos e qualidade do produto final.

Assim, ressalta-se no caso estudado o contraste das restrições de recursos, espaço e tempo para analisar e implementar mudanças. A empresa analisada opta, muitas vezes, por aprender com a 
própria experiência e empirismo no gerenciamento de seus processos com a sua estratégia baseada na diferenciação através da busca constante por um controle de qualidade eficiente e satisfação dos clientes - ainda que tal estratégia signifique, por vezes, aumentar tempos de produção. Isso representa parte da sobrevivência da empresa, em virtude do mercado de atuação volátil no qual se encontra. As diversas inspeções de qualidade após montagem e os testes estão em consonância com a realidade de certificações ISO obtidas pela companhia, embora não gerem perdas significativas.

Um dos pontos mais críticos que afeta um processo saudável de inspeções, gera retrabalho e é puxador de diversas perdas é a relação com a cadeia de fornecedores chineses, os quais primam pelos baixos custos mas não oferecem as garantias de qualidade necessárias ao padrão de entregas da empresa. Interpretado em uma visão macroambiental, esse ponto afeta não apenas a empresa em questão, mas o setor inteiro de tecnologia ao qual a empresa se vincula. Em se tratando de PMEs, torna-se ainda mais crítico, pois implica em decisões estratégicas cruciais sobre seus estoques e seus tempos de produção e entregas - que, assim, distanciam-se cada vez mais do conceito referencial de just-in-time do Sistema de Gerenciamento Lean. Entender esses pontos críticos é fundamental ao se considerar o momento de desenvolvimento econômico do País no qual se busca investir na capitalização tecnológica e no fortalecimento do setor de tecnologia como um todo - incluindo-se fornecedores, parceiros de negócios estratégicos, clientes e governos.

Ampliando-se a perspectiva em relação ao tema, acredita-se que o presente trabalho contribui para somar uma análise qualitativa não apenas em relação a uma empresa específica, mas também sobre as dificuldades e incertezas das PMEs nacionais de tecnologia. Tal qual evidenciado a princípio, faltam trabalhos científicos na área, assim como são escassas as ferramentas de avaliação lean em PMEs. Mantém-se a ressalva de que mais pesquisas precisam ainda ser realizadas para que modelos de pequenos e médios negócios possam se consolidar de maneira enxuta. Outros métodos devem ser trabalhados nessa linha de pesquisa, a fim de eliminar aspectos subjetivos e particulares inerentes a estudos de caso de âmbito qualitativo - caso deste estudo. Os primeiros passos em direção ao Sistema de Gerenciamento Lean já foram dados, contudo, falta ainda que se assuma esse sistema de uma forma estratégica, englobando a organização em nível corporativo. Logo, sugere-se outras pesquisas na área, a fim de compor-se um panorama mais completo do Sistema de Gerenciamento Lean em PMEs.

\footnotetext{
Abstract

The present study aimed to assess the seven major losses in production processes of a small company through the Lean Management System. Following an exploratory methodology, qualitative, through a case study in which they were cross-analyzed of information obtained through observation, visits in the company, interviews with managers, and an application of a checklist for implementation of lean practices. The results of the main losses were shown in a case study in
} 
relation to the national context of technology for small and medium enterprises (SMEs), moving over a field of study still open and needed in Brazil. It was emphasized the fact that the company adopts some practices of lean production associated with pushed practices, in a production composition that is traditional in this kind of industry. In this context, the main losses identified overproduction, processing, waiting, inventory, defective products - are consistent with the reality of weakness in the integration with the supply chain, the balancing of production and continued production.

Keywords: qualitative assessment; small and medium enterprises; lean management system.

\section{Referências}

ACHANGA, P. SHEHAB, E.; ROY R. E NELDER, G. Critical success factors for lean implementation within SMEs. Journal of Manufacturing Technology Management, Cranfield, Reino Unido, v. 17, n. 4, p. 460-471, 2006.

DE TREVILLE, S.; ANTONAKIS, J. (2006). Could lean production job design be intrinsically motivating? Contextual, configura- tional, and levels-of-analysis issues. Journal of Operations Management, v. 24, n. 2, p. 99-123, 2006.

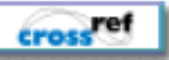

EMILIANI, M. L.; STEC., D. J. Leaders lost in transformation. Leadership and Organization Development Journal, New Britain (EUA), v. 26, n. 5, p. 370-387, 2005.

FERREIRA, C.; SAURIN, T. Avaliação qualitativa da implantação de práticas da produção enxuta: estudo de caso em uma fábrica de máquinas agrícolas. Revista Gestão e Produção, São Carlos, v. 15, n. 3, p. 449-462, 2008.

FURINI, G. SAURIN, T. Proposta de um método de análise da cultura lean em uma empresa que está implantando práticas do sistema de produção enxuta. In: ENCONTRO NACIONAL DE ENGENHARIA DE PRODUÇÃO ENEGEP, 28., 2008, Rio de Janeiro. Anais... Rio de Janeiro, 2008.

HINES, P.; HOLWEG, M.; RICH, N. Learning to evolve: a review of contemporary lean thinking. International Journal of Operations \& Production Management, v. 24, n.10, 994-1011, 2004.

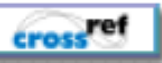

LAUGEN, B. T.; BOER, H. The implementation of best practices: process and performance effects. Journal of Creativity and Innovation Management, v. 16, n. 4, p. 397-407, 2007.

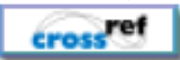

LEAN INSTITUTE BRASIL. Disponível em: <http://www.lean.org.br>. Acesso em: julho de 2011.

LIMA, M. L. S. C.; ZAWISLAK, P. A. A produção enxuta como fator diferencial na capacidade de fornecimento de PMEs. Revista Produção, v. 13, n. 2, 2003.

NARETTO, N.; BOTELHO, M. R.; MENDONÇA, M. A trajetória das políticas públicas para pequenas e médias empresas no Brasil: do apoio individual ao apoio a empresas articuladas em arranjos produtivos locais. Revista Planejamento e Políticas Públicas, Brasília, n. 27, p. 61-115, 2005.

OHNO, T. O Sistema Toyota de Produção: além da produção em larga escala. Porto Alegre: Bookman, 1997.

OLAVE, M. E. L.; AMATO NETO, J. Redes de cooperação produtiva: uma estratégia de competitividade e sobrevivência para pequenas e médias empresas. Revista Gestão e Produção, São Carlos, v. 8, n. 3, p. $289-303,2001$.

PORTER, M. Estratégia competitiva: técnicas para análise de indústrias e da concorrência. Rio de Janeiro: Campus, 1997.

SCAFFEDE, R. What it takes to turn manufacturing lean: the experience of Donnelly Corporation. Journal of Organizational Excellence, v. 21, n. 4, p. 3-16, 2002. 
Serviço Brasileiro de Apoio às Micro e Pequenas Empresas - SEBRAE (org.); departamento intersindical de estatística e estudos socioeconômicos - DIEESE. Anuário do trabalho na micro e pequena empresa. 3 ed. São Paulo, Brasília: SEBRAE; DIEESE. 2009. Disponível em: <http://gestaoportal.sebrae.com.br/customizado/estudos-e-pesquisas/temasestrategicos/emprego/anuario_trabalho_2009.pdf>. Acesso em: julho de 2011.

SHAH, R., \& WARD, P. T. (2003). Lean manufacturing: Context, practice bundles, and performance. Journal of Operations Management, v. 21, n. 2, 129-149, 2003.

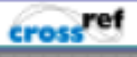

SHAH, R.; WARD, P. T. Defining and developing measures of lean production. Journal of Operations Management, v. 25 , n. 4, p. $785-805,2007$.

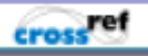

SCHERRER-RATHJE, M.; BOYLE, T. A.; DEFLORIN, P. Lean, take two! Reflections from the second attempt at lean implementation. Business Horizons, v. 52, p. 79-88, 2009.

\section{cross ref}

SHINGO, S. O sistema toyota de produção: do ponto de vista da engenharia de produção, Porto Alegre: Bookman, 1996.

SILVA NETO, R. A crescente importância econômica das pequenas empresas no Brasil a partir da reestruturação industrial. Vértices, ano 3, n. 1, p. 11-18, 2000. Disponível em:

<http://www.essentiaeditora.iff.edu.br/index.php/vertices/article/view/155/141>. Acesso em: julho de 2011.

VEIGA, G. L.; LIMA, E. P.; COSTA, S. E. G. Uma discussão sobre o papel estratégico do Modelo de Produção Enxuta. Revista Eletrônica Sistemas e Gestão, v. 2, n. 2, p. 92-113, 2008. Disponível em:

<http://www.uff.br/sg/index.php/sg/article/viewFile/SGV3N2A2/53>. Acesso em: julho de 2011.

WOMACK, J. P.; JONES, D. T.; ROOS, D. A máquina que mudou o mundo. Rio de Janeiro: Campus, 1992.

YIN, R. K. Case study research: design and methods. 4 ed. Thousand Oaks (EUA): Sage, 2009.

\section{Dados dos autores:}

Nome completo: Giana Carli Lorenzini

Filiação institucional: Universidade Federal do Rio Grande do Sul

Departamento: DEPROT - Departamento de Engenharia de Produção e Transportes

Função ou cargo ocupado: Mestranda

Endereço completo para correspondência (bairro, cidade, estado, país e CEP): Av. Osvaldo Aranha, $99-5^{\circ}$ andar. Bairro Centro. Porto Alegre. RS. CEP 90.035-190

Telefones para contato: (51) 9824.2842

e-mail: giana@producao.ufrgs.br

\section{Nome completo: Tarcísio Abreu Saurin}

Filiação institucional: Universidade Federal do Rio Grande do Sul

Departamento: DEPROT - Departamento de Engenharia de Produção e Transportes

Função ou cargo ocupado: Professor

Endereço completo para correspondência: Av. Osvaldo Aranha, 
$99-5^{\circ}$ andar. Bairro Centro. Porto Alegre. RS. CEP 90.035-190

Telefones para contato: (51) 9628-2554

e-mail: saurin@ufrgs.br

Nome completo: Fernando Gonçalves Amaral

Filiação institucional: Universidade Federal do Rio Grande do Sul

Departamento: DEPROT - Departamento de Engenharia de Produção e Transportes

Função ou cargo ocupado: Professor

Endereço completo para correspondência: Av. Osvaldo Aranha,

$99-5^{\circ}$ andar. Bairro Centro. Porto Alegre. RS. CEP 90.035-190

Telefones para contato: (51) 3308-4292

e-mail: amaral@producao.ufrgs.br

Submetido em: 30/07/2012

Aceito em: 27/09/2013 